University of Wollongong

Research Online

Faculty of Engineering and Information

Faculty of Engineering and Information

Sciences - Papers: Part B

Sciences

2017

Simulation of particle deformation within a compressed packed bed

Leela M. Kempton

University of Wollongong, leelak@uow.edu.au

David J. Pinson

BlueScope Steel Limited, DavidJ.Pinson@bluescopesteel.com

Sheng Chew

University of Wollongong, shengc@uow.edu.au

Paul Zulli

University of Wollongong, paulz@uow.edu.au

Aibing Yu

Monash University

Follow this and additional works at: https://ro.uow.edu.au/eispapers1

Part of the Engineering Commons, and the Science and Technology Studies Commons

Research Online is the open access institutional repository for the University of Wollongong. For further information contact the UOW Library: research-pubs@uow.edu.au 


\title{
Simulation of particle deformation within a compressed packed bed
}

\author{
Abstract \\ Deformation arising from softening-melting conditions in the blast furnace has provided a significant \\ challenge to numerical modelling. In this paper, a sub-particle discrete element approach is used to \\ simulate a bed of particles deforming under load at a constant temperature. Effects of temperature on \\ material properties are established through the use of simulations of material under compression, with \\ the results compared to experimental data. This was used as a starting point for the packed bed \\ simulations at different temperatures, with the ratios between parameters maintained. Porosity within the \\ final bed was used as a measure of the deformation, and compared to previous low temperature \\ experimental work. The nature of the modelling technique allowed for visual analysis of the deformation \\ of individual macro-particles within the packed bed. Numerical results for the stabilised final porosity \\ were comparable for a variety of loads for a given set of parameters demonstrating that this technique is \\ suitable for modelling plastically deformable granular materials.

\section{Disciplines} \\ Engineering | Science and Technology Studies

\section{Publication Details} \\ Kempton, L., Pinson, D., Chew, S., Zulli, P. \& Yu, A. (2017). Simulation of particle deformation within a \\ compressed packed bed. Powder Technology, 320 586-593.
}




\title{
Simulation of Particle Deformation within a Compressed Packed Bed
}

\author{
Leela Kempton ${ }^{1,2}$, David Pinson ${ }^{2}$, Sheng Chew $^{2}$, Paul Zulli ${ }^{2,3}$ and Aibing $\mathbf{Y u}^{1,4}$ \\ ${ }^{1}$ School of Materials Science and Engineering, University of New South Wales, \\ Sydney, NSW 2052, Australia \\ ${ }^{2}$ BlueScope Steel, Port Kembla, NSW 2505, Australia. \\ ${ }^{3}$ School of Mechanical, Materials and Mechatronics Engineering, University of Wollongong, \\ Wollongong, NSW 2522, Australia \\ ${ }^{4}$ Laboratory for Simulation and Modelling of Particulate Systems, Department of Chemical \\ Engineering, Monash University, Clayton, VIC 3800, Australia \\ ${ }^{*}$ Corresponding author: David.Pinson@bluescope.com
}

\begin{abstract}
Deformation arising from softening-melting conditions in the blast furnace has provided a significant challenge to numerical modelling. In this paper, a sub-particle discrete element approach is used to simulate a bed of particles deforming under load at a constant temperature. Effects of temperature on material properties are established through the use of simulations of material under compression, with the results compared to experimental data. This was used as a starting point for the packed bed simulations at different temperatures, with the ratios between parameters maintained. Porosity within the final bed was used as a measure of the deformation, and compared to previous low temperature experimental work. The nature of the modelling technique allowed for visual analysis of the deformation of individual macro-particles within the packed bed. Numerical results for the stabilised final porosity were comparable for a variety of loads for a given set of parameters.
\end{abstract}

Keywords: Compression, DEM, deformation, softening-melting.

\section{Introduction}

A key factor in the behaviour of softening-melting materials in the blast furnace is their response to compressive load. Materials in the blast furnace undergoing softening-melting are exposed to significant compressive forces from the load of the burden above them. Typically, as the ferrous materials soften, the porosity of the layer decreases until it becomes impermeable. This has important ramifications for the gas flow through the blast furnace and is one of the key features of the cohesive zone which affects the operation of the blast furnace as a whole. It is also the reason why materials are charged in layers to ensure that there remain open channels of permeable coke to provide a path of minimal resistance for the gas flow [1].

The presence of compressive forces on the ferrous layer also complicates the study of how the materials soften as it becomes difficult to analyse the individual contributions of the competing factors affecting softening including temperature, load and composition. Experimental softening-melting tests are used to study the softening properties of burden materials by heating a bed of ore particles under specified temperature and reducing gas conditions, and monitoring the reduction and pressure drop across the bed [2]. However, it has been recognised that it is not practical to exactly replicate the exact blast furnace conditions in these tests [3]. It has also been shown that the softening-melting properties of burden materials are influenced by a combination of factors rather than single factors [4]. As a result, the majority of softening-melting test results [5-8] have focused primarily on the overall properties of the bed such as pressure drop and temperatures at which changes in the pressure drop occur, rather than the effect of softening on the structure and composition of the bed.

Powder Technology 320C (2017) pp. 586-593 DOI information:

http://dx.doi.org/10.1016/j.powtec.2017.07.082 
Low temperature experiments of softening-melting have instead been developed to provide a practical means of examining the formation and interaction of cohesive layers in materials to improve understanding of the cohesive zone. Chew [9] developed experiments to simulate the softening-melting conditions in the blast furnace using low melting point paraffin wax as an analogue for iron ore. This was extended by Maldonado [10] to consider wax balls and glass beads to examine the layered structure of the blast furnace cohesive zone. Both these studies focused primarily on the macroscopic effects of softening and melting on layers within packed beds. Subsequently, Zheng [11] investigated the effects of temperature and load pressure on softening-melting behaviour of a packed bed under a compressive load, with the bed geometry sized to match the BHP softening-melting test rig [12]. In Zheng's study, wax balls at a specified temperature were exposed to a known compressive force and the response of the bed was monitored over time to examine the bulk change in porosity of the bed as the particles deformed. Variables such as the melting point of the wax, composition of the bed, load and temperature were analysed for their effect on the deformation process of the bed.

The controlling deformation mechanism in Zheng's experimental work was found to be creep deformation, as the bed of wax particles was exposed to a low temperature over a prolonged period of time. Whilst study on deformation mechanisms of packed beds is limited, it has been proposed that deformation can occur through either rearrangement of the particles, dislocation of the particles or elastic (reversible) deformation [13]. Creep effects on packed beds have not been widely investigated, and the contributing factors such as stress, temperature and time have not been established [14]. In addition to this, the conditions of the softening-melting test, and indeed the cohesive zone of the blast furnace, differ from the wax packed bed experimental test conditions as the temperature is constantly increasing and material is not held at a single temperature for a prolonged period of time. Therefore analysis of the numerical simulation needs to consider these differences.

A previous attempt to simulate the softening-melting test using discrete element method (DEM) [15] focussed on structural rearrangement by reducing the stiffness of the particles and allowing large overlaps between soft particles (and conversely, small overlaps between hard particles). However, this was recognised as a very crude and limited representation as it did not account for the interparticle forces and physical shape change of the particles. Instead, a sub-particle DEM approach developed to simulate macroscopic deformation effects [16] has been extended and applied to a packed bed of deformable particles in order to simulate the response of the packed bed to a compressive load. As such, the bulk observations of Zheng [11] can be explored. This computational method provided significant information both on the change in shape and structure of individual particles as they underwent softening-melting as well as macroscopic information on the packed bed as a whole. As with other DEM simulations, the challenge of appropriate parameter selection to ensure realistic results is present. This has been achieved for other DEM applications through the use of simplistic simulations that can easily be replicated experimentally using the materials under investigation, such as sand pile formation [17]. The sub-particle model, however, is complicated by the need to produce a range of temperature dependent behaviours from brittle response through to ductile deformation. It is therefore imperative that the parameters chosen for the model are validated and the impacts of variations to these parameters are well understood.

\section{Simulation Conditions}

\subsection{Governing Equations}

The sub-particle DEM model was developed to simulate macro-scale deformation of particles by representing a particle as an agglomeration of sub-particles held together by a bonding force. Individual particles are simulated in the classical method using DEM [18]. The fundamental basis of DEM is solving Newton's second law of motion at a discrete level, that is, for individual particles. Forces are calculated at contact points between particles, as well as between particles and walls, in both the normal and tangential directions. Externally acting forces, such as gravity, are also considered. The equations for conservation of momentum are then solved in the translational and rotational fields, as given in Equation 1.

$m_{i} d \boldsymbol{v}_{i} / d_{t}=\sum \boldsymbol{F}_{N, i}+\sum \boldsymbol{F}_{T, i}+\boldsymbol{F}_{G, i}$

Powder Technology 320C (2017) pp. 586-593 DOI information:

http://dx.doi.org/10.1016/j.powtec.2017.07.082 
Once the forces have been calculated for each particle, the velocity Verlet method [19] is used to determine the resultant change in velocity and position of the particles at each timestep. Normal forces are calculated by the linear spring-dashpot model, [18] as shown in Equation 2.

$\boldsymbol{F}_{N}=-K_{N} \delta-\boldsymbol{F}_{D}$

$\boldsymbol{F}_{D}=-C_{N} \boldsymbol{v}_{r e l}$

Bonding forces between the sub-particles are represented by a bond strength value $R_{N B}$ [20]. This bond strength is added directly to the forces calculated from the linear spring dashpot model, as given in Equation 4. This model also includes a bond rolling resistance to prevent particles with a solid bond rotating against each other.

$\boldsymbol{F}_{N}^{\prime}=\boldsymbol{F}_{N}+\boldsymbol{F}_{D}+R_{N B}$

In the tangential direction, the force is calculated by considering the shear stress using the method proposed by Cundall \& Strack [18] as given in Equation 5. However, an additional tangential bond strength $R_{T B}$ is included in the sliding criterion, increasing the sliding limit.

$\boldsymbol{F}_{T}=K_{T} \delta+\boldsymbol{F}_{D, s}$

if $\boldsymbol{F}_{T} \geq F_{T p e a k}=\mu \boldsymbol{F}_{N}+R_{T B}$ then $\boldsymbol{F}_{T}=\mu \boldsymbol{F}_{N}$

\subsection{Parameter Determination}

The first step in simulating a packed bed of agglomerates deforming under load is determining the required parameters as a function of the temperature being considered. Temperature is not considered directly in the simulation, rather the bonding properties thought to be influenced by temperature including spring constant, normal bond strength, tangential bond strength and friction factor are varied to account for temperature affects. To test this approach, simulations using compression and tensile stress have been used to determine appropriate parameter selection, with literature results for tensile strength and elongation at a set temperature used to validate these results. A reasonable approach is to then maintain the ratio of parameters constant as effects of temperature are considered. There have been a limited number of studies using DEM to simulate agglomerates under compression [21-24], with the focus mainly on fracture mechanisms and surfaces obtained following fracture. Here, however, the focus in on understanding how the parameters influence the required material behaviour under ductile conditions.

The material being considered in the simulations is paraffin wax, as it exhibits the temperature dependant ductile behaviour. It is also the material used in the packed bed deformation studies being replicated in this paper [11]. Rheological investigations of paraffin wax have shown a transition temperature as a function of the melting point, corresponding to a marked weakening of paraffin waxes and an increase in the elongation. Wang et al. [25] conducted tensile tests of paraffin wax at 15,25 and $30^{\circ} \mathrm{C}$, with a marked transition from brittle behaviour at $25^{\circ} \mathrm{C}$ to ductile behaviour at $30^{\circ} \mathrm{C}$. Accompanying this transition was a sharp decrease in the absolute tensile strength of the material and a significant increase in the elongation experienced prior to fracture. Thus for the ductile behaviour desired, a temperature of $30^{\circ} \mathrm{C}$ has been chosen.

Common material properties were used for the sub-particles in the parameter tests as well as the packed bed simulation. The temperature dependant bonding parameters were determined by trial and error to match experimental results. These values were then varied for the packed bed simulations, maintaining the same ratio between the parameters, to simulate the temperature conditions required. Values for the parameters used, as well as the packed bed geometry parameters are listed in Table 1.

Table 1: Simulation parameters

Variable

Sub particle radius
Symbol

$r_{i}$
Value

$5.5 \times 10^{-4} \mathrm{~m}$

Powder Technology 320C (2017) pp. 586-593 DOI information:

http://dx.doi.org/10.1016/j.powtec.2017.07.082 
Particle density

Time step

*Normal spring constant

*Normal bond strength

*Tangential bond strength

*Sliding friction coefficient

$\begin{array}{ll}\rho & 900 \mathrm{~kg} \cdot \mathrm{m}^{-3} \\ D T & 1 \times 10^{-7} \mathrm{~S} \\ K_{N} & 8.0 \times 10^{4} \mathrm{~N} \cdot \mathrm{m}^{-1} \\ R_{N B} & 1.6 \\ R_{T B} & 1.6 \\ \mu_{s} & 0.04\end{array}$

*Note: These values are base values only and were varied in the simulations

\subsection{Packed Bed Generation}

The packed bed simulation is based on the experimental results of Zheng [11], which involved a packed bed of deforming particles under a load at a constant temperature. The main area of interest in the packed bed simulations was the response of the packed bed at different temperatures to various loads applied. Each of the experiments was allowed to proceed over a lengthy time period to achieve a final equilibrium outcome where no further displacement of the bed could be observed. In some conditions, the softening-melting proceeded to completion, that is, there was no remaining porosity in the bed. In the numerical simulations, the result of most interest was the final condition of the packed bed when it had reached equilibrium. Porosity within the packed bed was calculated as per Equation 6, and used to determine the extent of deformation within the bed.

$\varepsilon=1-V_{\text {Agglomerates }} / V_{B e d}=1-N_{\text {Agg }} \times 4 / 3 \times \pi R_{\text {Agg }}{ }^{3} /\left(\pi R_{C y}{ }^{2} H_{B e d}\right)$

The sub-particle model developed previously [16] involves the creation of an agglomerate of subparticles held together by a bonding force to represent a single macro particle. In this paper, a cylindrical packed bed was formed by creating a specified number of agglomerates (136), with a radius of $5.5 \times 10^{-3} \mathrm{~m}$ one at a time within the defined space of a cylinder height $0.165 \mathrm{~m}$ and radius $0.0255 \mathrm{~m}$. Gravitational forces were then applied to the agglomerates and they were allowed to settle until at rest. This packed bed formation was used as the starting condition in all subsequent simulations. After the settling process, the bonding parameters were varied in small increments until a set value was reached. The nominated load was then applied to the surface of the packed bed and the height of the surface of the packed bed was monitored as the load compressed the bed. A schematic of the experiment and photo of the experimental packed bed is given in Figure 1, alongside a picture of the same size DEM packed bed. 

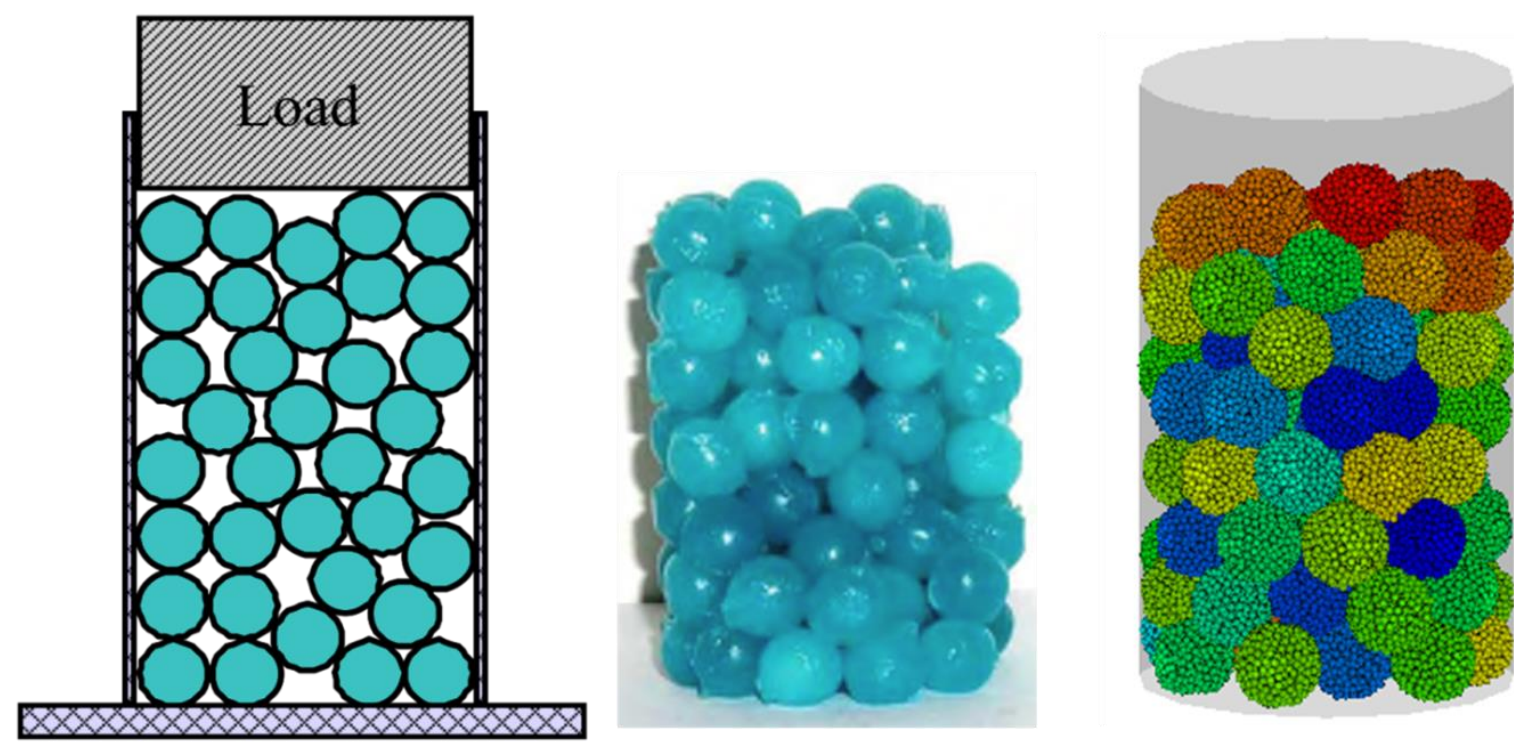

Figure 1: Comparison of a schematic of the packed bed assembly (left), photo of the deformed wax particle bed [11] (middle) and DEM simulation of the packed bed (right) - particles coloured by agglomerate number.

\section{Validation of Bonding Parameters}

Appropriate validation of the bonding parameters selected is vital for the reliability of the subsequent simulations. A major advantage of the sub-particle approach is the ability to simulate geometries of any shape and size, whilst maintaining the simulation parameters for the individual sub-particles. This has allowed for the possibility of simulating known physical material tests, which allow for validation of the parameter results under ductile conditions. In the work, two common material tests have been used for validation - firstly, a tensile test and secondly a uni-axial compression test. Experimental results for paraffin wax under these standard test conditions are readily available, allowing for reliable validation of the simulation parameter selection.

\subsection{Tensile Test}

A standard material tensile test is commonly used to test the strength and ductility properties of a material [26]. In this test, a specimen consisting of a cylinder of material is subjected to an increasing uniaxial force whilst the elongation of the specimen is monitored. The resultant stress-strain curve produced, as shown in Figure 2, can be used to analyse various properties of the material including yield stress, tensile strength, fracture point and elongation. In the simulation, the tensile stress is achieved by applying a constant strain rate to either end of the material. Engineering stress [26] is calculated based on the sum of forces acting on particles at the edge of the test piece divided by the average original cross-sectional area of the test piece. Strain, also referred to as elongation in the tensile test, is monitored by the change in length of the test piece as a percentage of the original length. 


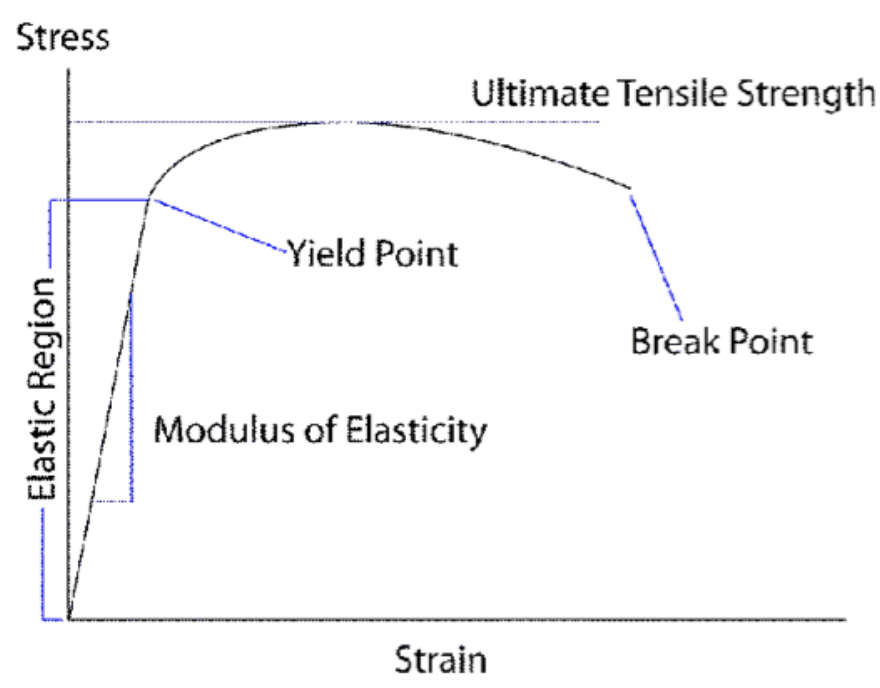

Figure 2: Stress-strain diagram of a tensile test [27]

The tensile test was used for validation by simulating a cylindrical sample with a radius of $0.0055 \mathrm{~m}$ and a length of $0.077 \mathrm{~m}$. A total of 5250 sub-particles were used to create the specimen, which resulted in an average coordination number of 5.26. This is in line with dense agglomerates that have been shown to produce a more distinct fracture behaviour compared to loose agglomerates, which tend to disintegrate $[21,28]$. The edges of the specimen were subjected to an imposed movement of $0.1 \mathrm{~m} . \mathrm{s}^{-1}$ to simulate a constant strain rate and the response of the remainder of the sub-particles within the specimen was monitored. Results showing the stress and strain calculated over the simulation, as well as the number of adhesive bonds broken plotted against the strain are given in Figure 3. Visual results of the simulation are given in Figure 4.
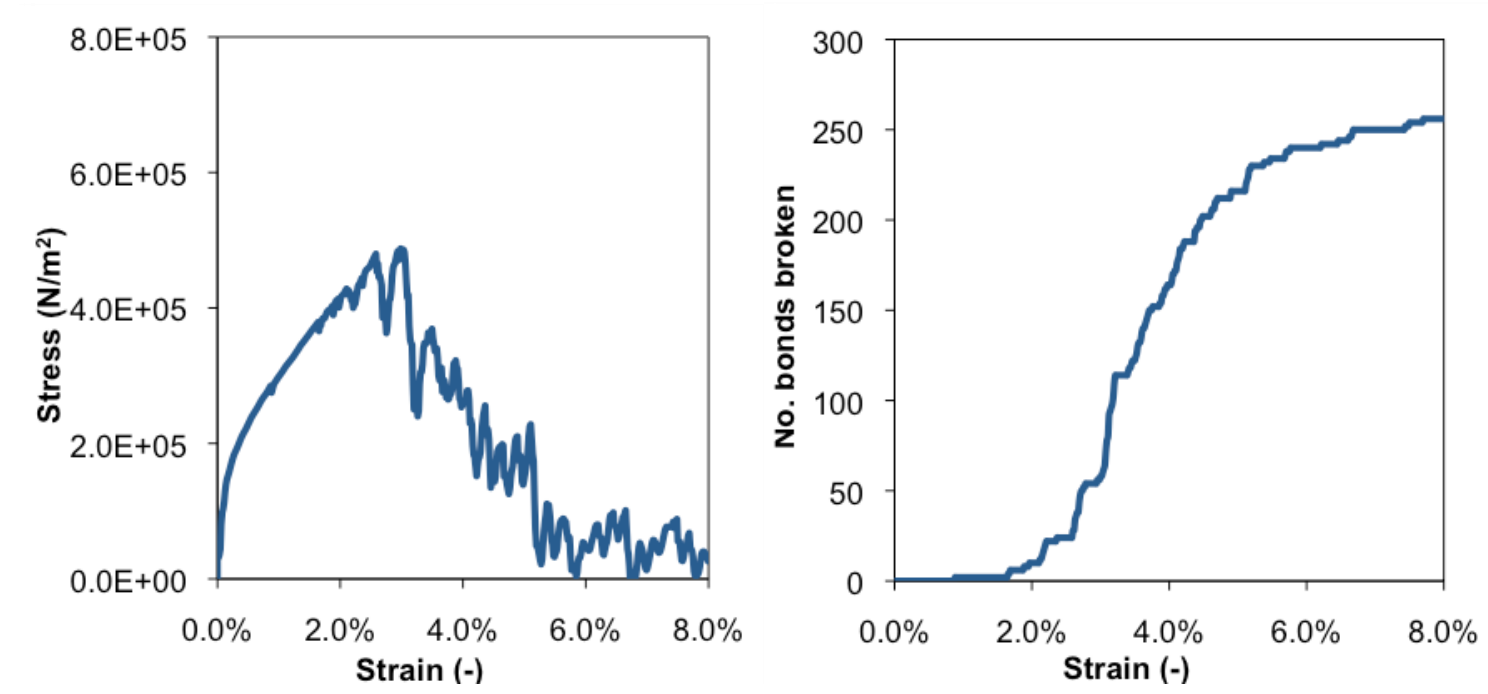

Figure 3: (a) Stress-strain relationship for tensile stress and (b) number of bonds broken versus strain 
(a)

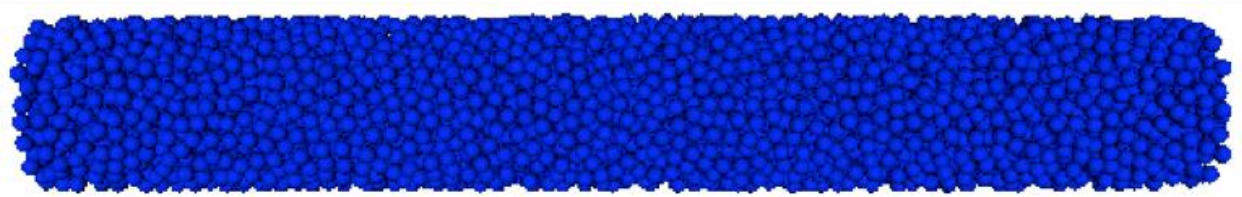

(b)

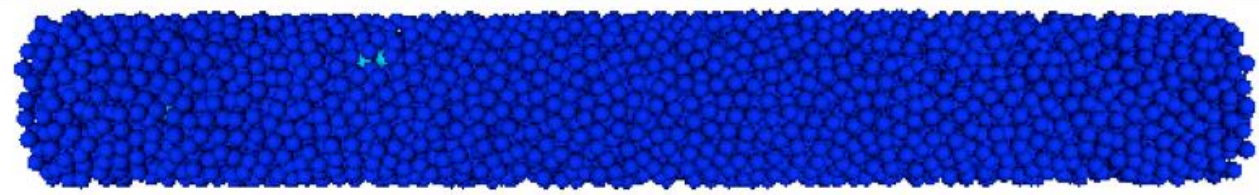

(c)

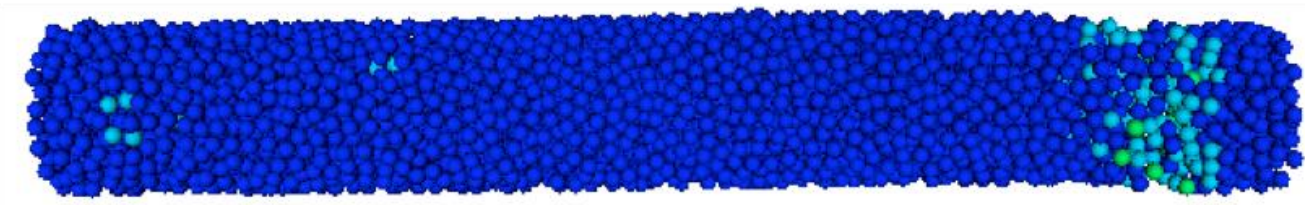

(d)

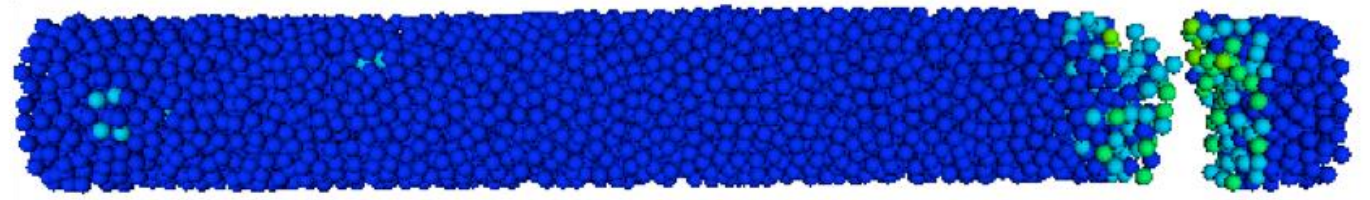

Figure 4: Visual results of separation for ductile conditions at strains of a) $0 \%$, b) $2 \%$, c) $5 \%$ and d) $\mathbf{1 0} \%$. Particles coloured by number of adhesive bonds broken.

As it can be seen, the linear portion of the stress strain curve is limited, with the yield strength of the material reached at around $1.4 \times 10^{5} \mathrm{~N} / \mathrm{m}^{2}$. Following this, a parabolic response to strain is seen until the maximum tensile strength of $4.9 \times 10^{5} \mathrm{~N} / \mathrm{m}^{2}$ is reached at a strain of $3.0 \%$. This is not a clear fracture, as it can be seen that the adhesive bonds continue to break progressively with the strain, allowing the material to continue to withstand lower amounts of stress while it continues to elongate. The final elongation reached by the simulation is around 6\%. Experimental results for paraffin wax $[25,29]$ show that the tensile strength drops dramatically above $25^{\circ} \mathrm{C}$ and at $30^{\circ} \mathrm{C}$ is shown to be around $5 \times 10^{5} \mathrm{~N} / \mathrm{m}^{2}$ at an elongation of almost $100 \%$. Although the tensile strength properties can be matched in the simulations, it was not possible to achieve the extreme elongation seen in the experimental results. To achieve a high level of elongation additional attraction forces between particles within the specimen that were not previously bonded would need to be considered. However for the purposes of the work covered by this paper, the level of elongation achieved was considered satisfactory.

\subsection{Compression}

Uni-axial compression was chosen as the second validation simulation as it provides a useful procedure for measuring the plastic flow behaviour and ductile fracture limits of a material, as well as the elastic and compressive fracture properties of brittle or low-ductility materials [19]. In this simulation, a spherical agglomerate was formed and then compressed between two planes which moved towards each other at a constant strain rate. The stress exhibited by the agglomerate on the planes was monitored and used to determine the compressive stress experienced by the agglomerate. The original cross-sectional area of the agglomerate was used as the basis of calculating the engineering stress. Strain was defined as the change in height of the particle relative to the original height. The sphere simulated in the compression test had a radius of $0.075 \mathrm{~m}$ and was constructed with a packing fraction of 0.5 , again to ensure a sufficiently dense agglomerate was created. This resulted in an agglomerate comprised of 1268 particles, with an average co-ordination number of 5.27 .

Uniaxial compression tests have been used on a cylinder of paraffin wax [30] with a change in the strain rate over the course of a test. A similar method was used to cover a temperature range of 29- 
$35^{\circ} \mathrm{C}$ by Rossetti et al. [31]. Above the temperature of $37^{\circ} \mathrm{C}$, the cylinders were found to collapse under their own weight.

Results showing the stress and strain calculated over the simulation are given Figure 5 . It can be seen from these results that a gradual increase in the stress is experienced until it plateaus at a stress of $5.5 \times 10^{5} \mathrm{Nm}^{-2}$. Figure $5 \mathrm{~b}$ shows the number of adhesive bonds broken with the strain experienced, which shows a small but steady number of bonds are broken as the sphere is compressed to allow for rearrangement of the particles as the agglomerate flattens.
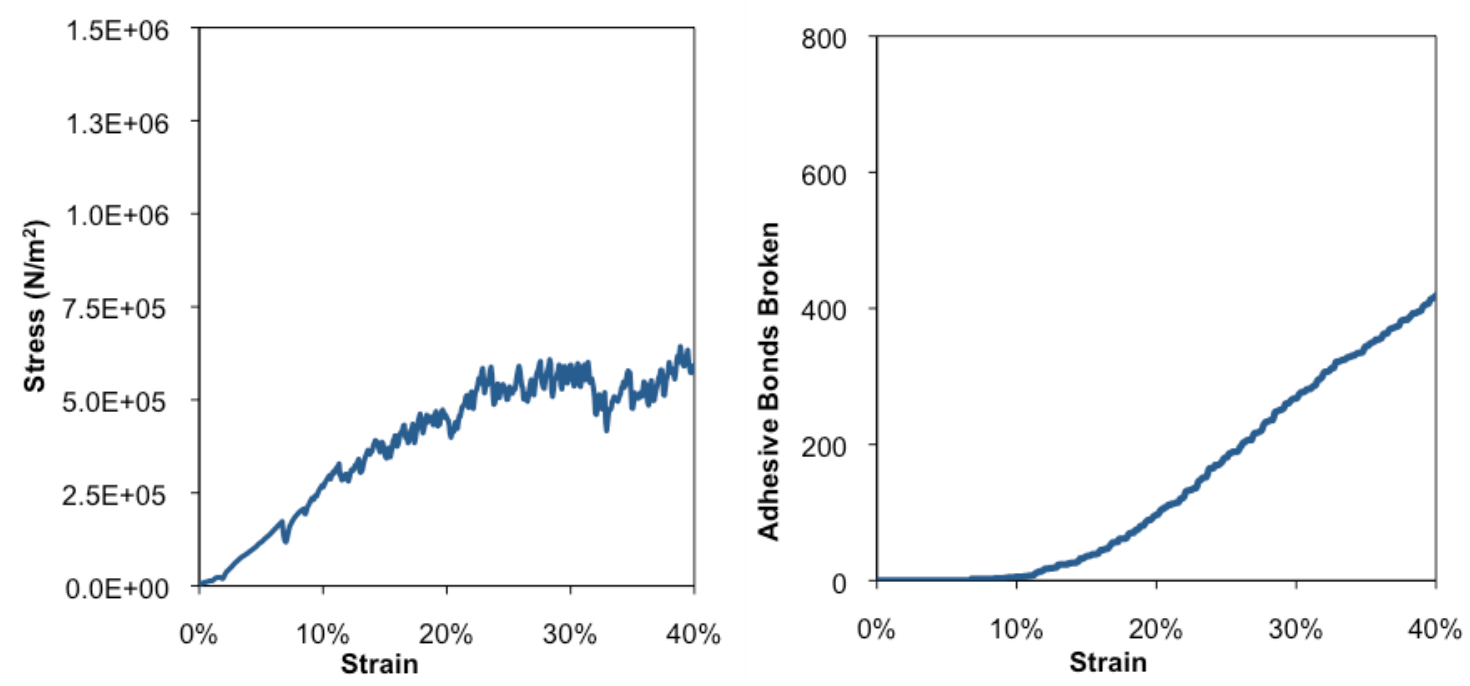

Figure 5: (a) Stress-strain relationships under compression and (b) Number of adhesive bonds broken compared to strain.

Visual results of the progression of the compression test are shown in Figure 6 at strains of $0 \%$ and $40 \%$. It can be seen that there are only a small number of bonds broken per particle at $40 \%$ strain, and this is considered insufficient to cause changes to the overall structure of the agglomerate. These results validate the choice of base ductile parameters for the subsequent simulations.

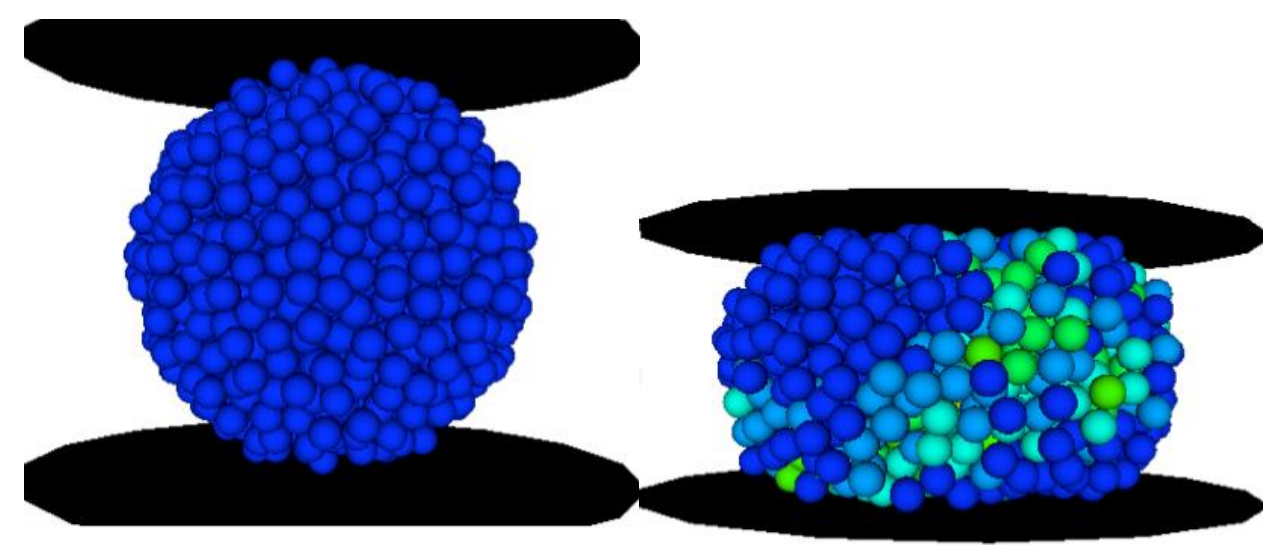

Figure 6: Visual results of compression at strains of a) $0 \%$, and b) $40 \%$. Particles are coloured by number of adhesive bonds broken.

\subsection{Packed Bed Temperatures}

Temperatures and load pressures considered were based on the experimental results of Zheng [11], which included temperatures of 35,37 and $39^{\circ} \mathrm{C}$ and load pressures of $0,0.1,0.3,0.6,0.8$ and $1 \mathrm{kPa}$. Parameters required to simulate the temperatures were determined by successive adjustment based on the base set of results determined previously for wax at $30^{\circ} \mathrm{C}$, with the ratio between the Powder Technology 320C (2017) pp. 586-593 DOI information:

http://dx.doi.org/10.1016/j.powtec.2017.07.082 
parameters maintained. The parameter values obtained are given in Table 2, along with the percentage factor applied to the base values. Figure 7 shows this factor compared to the differential temperature, taking $30^{\circ} \mathrm{C}$ as the base condition. It can be seen that there is an exponential relationship between the factor applied and the differential between the temperature and the softening start temperature.

Table 2: Parameter sets for varying temperatures

$\begin{array}{lllcll} & & 30^{\circ} \mathrm{C} & 35^{\circ} \mathrm{C} & 37^{\circ} \mathrm{C} & 39^{\circ} \mathrm{C} \\ \text { Spring constant } & K_{N} & 8.0 \times 10^{4} \mathrm{~N} \cdot \mathrm{m}^{-1} 9.6 \times 10^{3} \mathrm{~N} \cdot \mathrm{m}^{-1} & 4.0 \times 10^{3} \mathrm{~N} \cdot \mathrm{m}^{-1} & 1.2 \times 10^{3} \mathrm{~N} \cdot \mathrm{m}^{-1} \\ \text { (\% of base value) } & & & (12 \%) & (5 \%) & (1.5 \%) \\ \text { Normal bond strength } & R_{N B} & 1.6 & 0.192 & 0.08 & 0.024 \\ \text { Tangential bond strength } & R_{T B} & 1.6 & 0.192 & 0.08 & 0.024 \\ \text { Friction factor } & \mu_{S} & 0.04 & 0.0048 & 0.002 & 0.0006\end{array}$

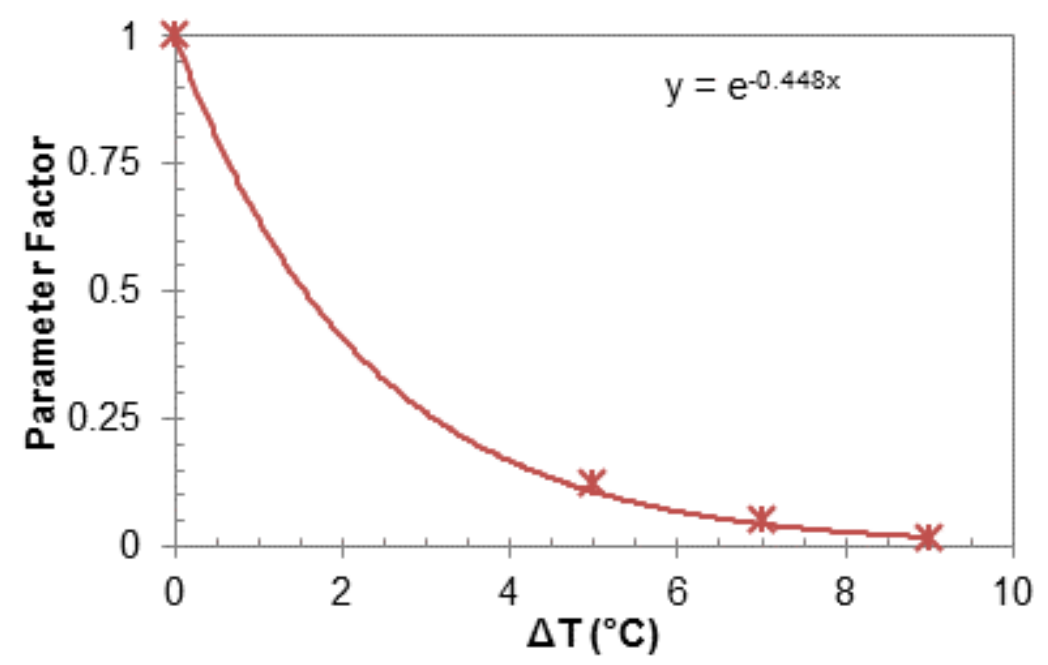

Figure 7: Parameter factor applied versus differential temperature

\section{Packed Bed Compression Results}

The packed bed simulated consisted of 136 agglomerates with an initial inter-agglomerate porosity of 0.41 . Results showing the change in porosity versus time for a range of loads at $35^{\circ} \mathrm{C}$ are given in Figure 8 alongside the experiment results for the same conditions. It can be seen that each simulation followed the same trend for reaching the steady state condition, with a roughly parabolic response followed by a levelling out of the porosity. Additionally the rate of change of porosity with time was independent of the load applied in the numerical simulations. In contrast, the experimental results show substantially more dependence on time, with an almost linear response of change in porosity over time, which, Zheng [11] concluded, demonstrates that the controlling mechanism for deformation in the experimental conditions is creep. 

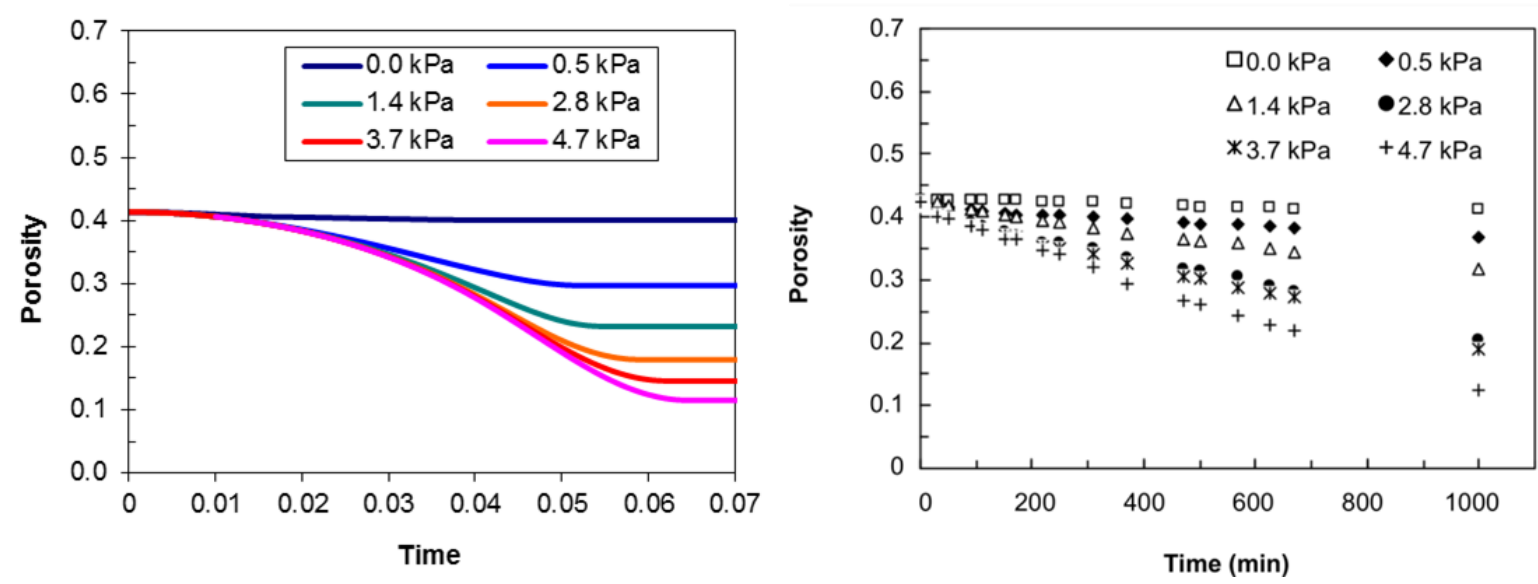

Figure 8: Change of porosity versus time at various load pressures at $35^{\circ} \mathrm{C}$ for numerical results (left) and paraffin wax experiments [11] (right)

Visualisations of the stabilised final position of the packed bed in response to each of the loads are given in Figure 9. Both the change in height as the load increases, as well as the effect of deformation on particle shape can be seen. Examining the change in structure of individual agglomerates as the various loads are applied allowed for the effect of load on deformation of individual particles to be investigated. Figure 10 shows the change in shape of a particular individual agglomerate, located towards the middle of the packed bed. As the same initial packing is used for all simulations, the effect of deformation in the same location at each pressure can thus be compared. The influence of surrounding particles in the bed can be seen in the resultant shape of the agglomerate as it exhibits flat spots on both the top left and bottom left edges. This figure also shows that this deformation is possible with only minimal rearrangement of the sub-particles.

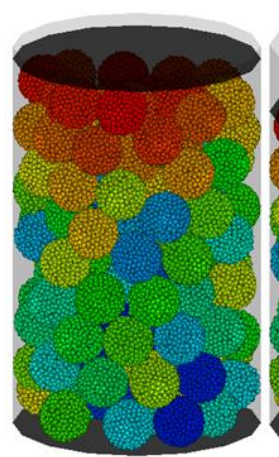

(a)

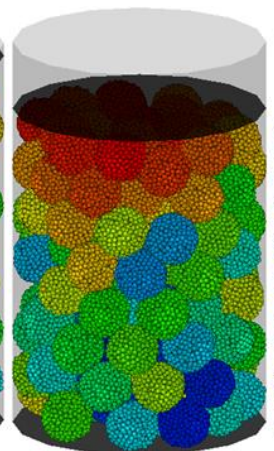

(b)

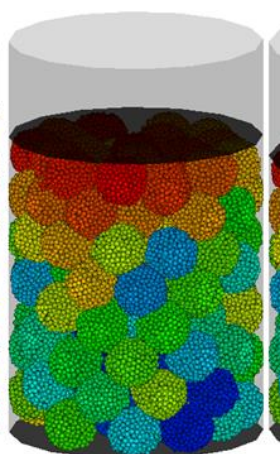

(c)

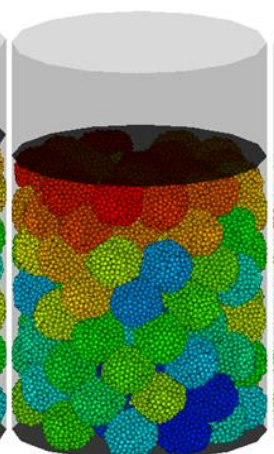

(d)

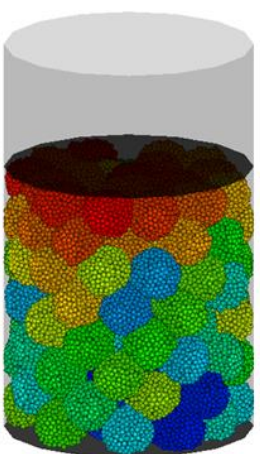

(e)

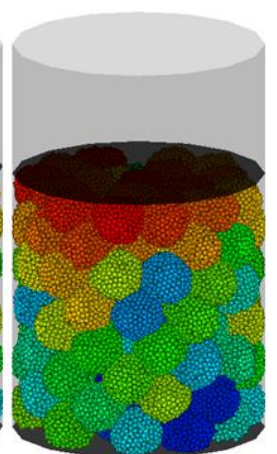

(f)

Figure 9: Visual results of final deformation of packed bed at $35^{\circ} \mathrm{C}$ from various load pressures - a) No load, b) 0.5 kPa, c) $1.4 \mathrm{kPa}$, d) $2.8 \mathrm{kPa}$, e) $3.7 \mathrm{kPa}$ and f) $4.7 \mathrm{kPa}$. Particles are coloured by agglomerate identification number. 


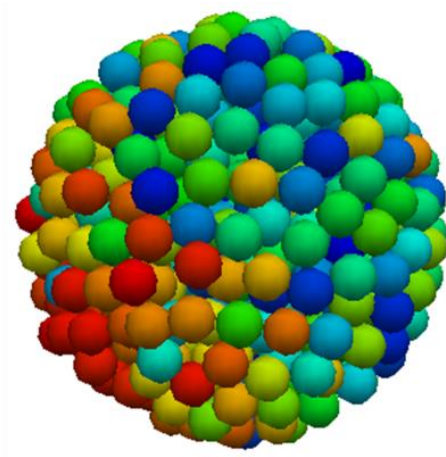

(a)

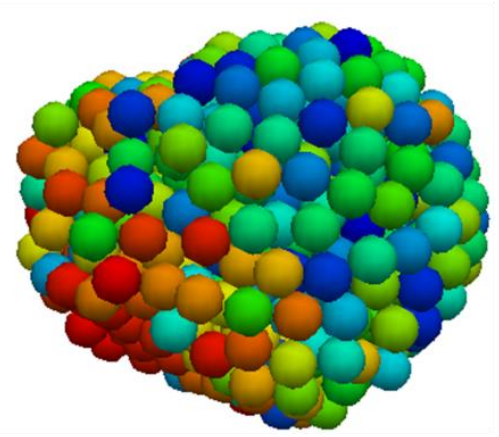

(d)

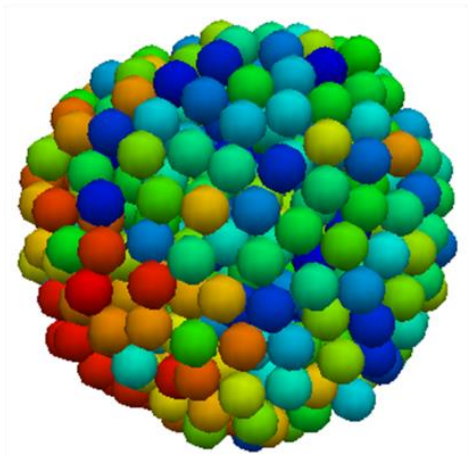

(b)

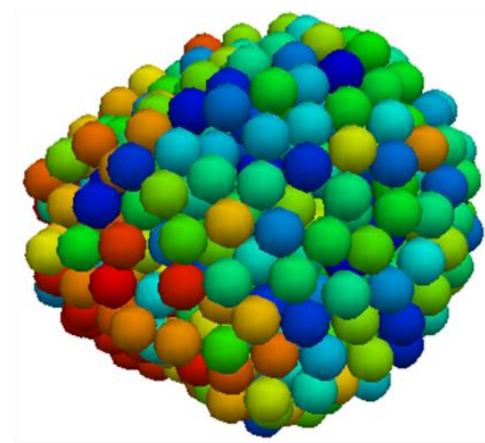

(e)

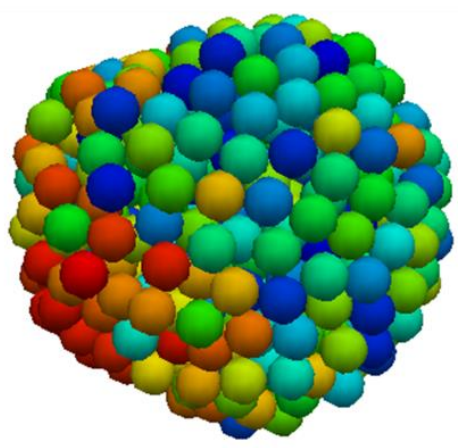

(c)

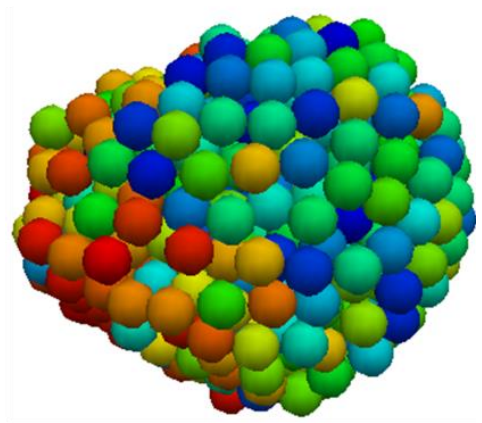

(f)

Figure 10: Individual agglomerate exhibiting deformation after load applied a) No load, b) $0.5 \mathrm{kPa}, \mathrm{c}) 1.4 \mathrm{kPa}$, d) $2.8 \mathrm{kPa}$, e) $3.7 \mathrm{kPa}$ and f) $4.7 \mathrm{kPa}$. Particles are coloured by identification number.

A comparison of the final porosity of the packed bed versus the load for different temperatures is given in Figure 11. It can be seen that the numerical results match the experimental data reasonably well, although there is some variation at lower load pressures, particularly for the $35^{\circ} \mathrm{C}$ experiment. Numerical results display a more parabolic relationship between load and porosity compared to the experimental results. Ultimately, however, these results show that the approach of varying the binding parameters exponentially with temperature, is able to reproduce the relationship between the porosity of the packed bed and the load experienced at a range of temperatures. 


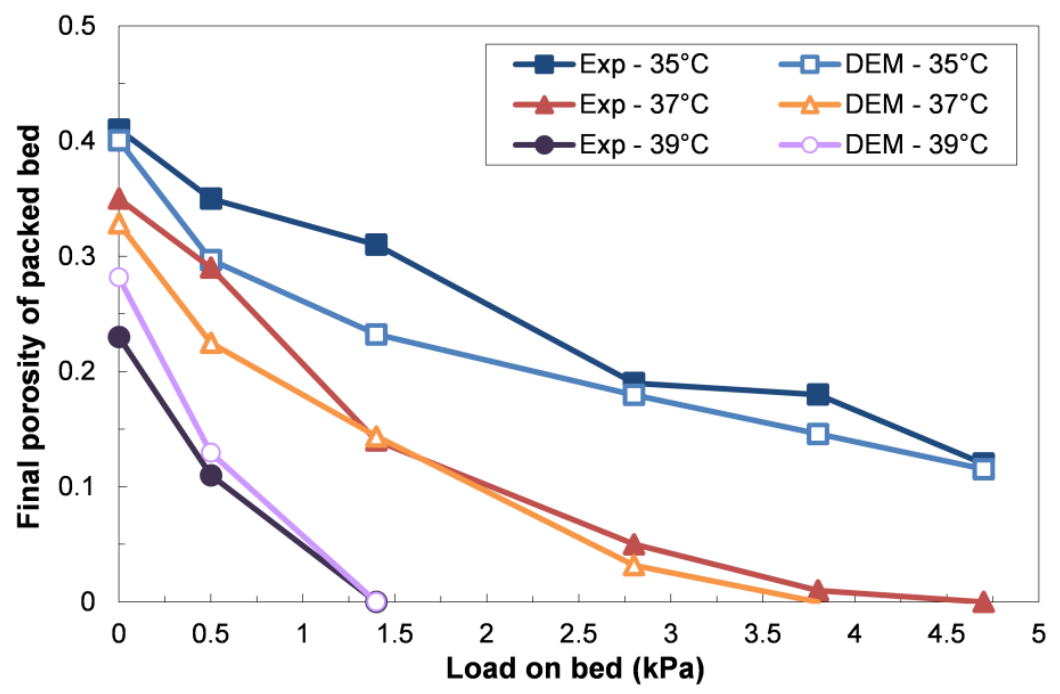

Figure 11: Comparison of final porosity versus load on bed for experimental and numerical results

These results demonstrate how the sub-particle DEM model can be used to simulate a range of material behaviour, with a particular focus on the ductile response seen under softening and melting conditions. Through varying the material properties as a function of the temperature of the material, the behavioural response of softening materials under experimental conditions was able to be replicated. This provides a good foundation for extending this work to consider the challenge of simulating layerwise meltdown conditions of the blast furnace cohesive zone.

\section{Conclusions}

A sub-particle DEM model was used to simulate a packed bed of wax particles deforming under load with the results compared to experimental results under the same conditions. Bonding parameters used in the simulation were validated through separate simulations of two common material tests- a tensile test and a compression test, highlighting the versatility of this approach. The simulations were able to replicate the endpoint stabilised final porosities of the packed bed experiments for a range of temperatures and load pressures, however progression of the deformation in the simulation appeared independent of the load applied which differed from the experimental results. Overall, the technique presented in this paper demonstrates a potential approach to modelling plastically deformable granular materials. Such technique should find wide application to general investigation of deformation dominated granular structures including economically significant systems like ferrous layer melt down that dominates blast furnace ironmaking control.

Acknowledgements

This research was supported under Australian Research Council's Linkage Projects funding scheme (LP0883512) and the support of BlueScope Ltd. is gratefully acknowledged.

\section{Nomenclature}

Symbol
$H_{C Y L}$
$K_{N}$
$N_{A g g}$
$N_{p}$
$r_{i}$
$R_{A g g}$
$R_{C Y L}$
$R_{N B}$

Description
Cylinder height
Normal spring constant
Number of agglomerates
Number of particles
Sub particle radius
Agglomerate radius
Cylinder radius
Normal bond strength

Units
N.m-1
m
$\mathrm{m}$
$\mathrm{m}$

Powder Technology 320C (2017) pp. 586-593 DOI information: http://dx.doi.org/10.1016/j.powtec.2017.07.082 


$\begin{array}{lll}R_{T B} & \text { Tangential bond strength } & \mathrm{N} \\ D T & \text { Time step } & \mathrm{S} \\ \varepsilon_{0} & \text { Initial porosity of packed bed } & \\ \mu_{s} & \text { Sliding friction coefficient } & \\ \rho & \text { Particle density } & \mathrm{kg} \cdot \mathrm{m}^{-3}\end{array}$

\section{References}

[1] Goldring, D.C., Jones, J.A. and Grebe, K., "Behaviour of Ferruginous Burden Material in Mannesmann N2 Quenched Blast Furnace", Ironmaking and Steelmaking, Vol.24, No.5, 1997, p.373-385.

[2] Ranade, M.G., "Testing of Softening and Melting Characteristics of Iron Bearing Materials: A Critical Review of Procedures and Applications", Ironmaking Conference Proceedings, Vol.42, 1983, p.129-144.

[3] Ono, K., Kushima, K. and Hida, Y., "Method of Evaluating the Quality of Pellets Used in Blast Furnace", Ironmaking Conference Proceedings, Vol.41, 1983, p.117-126.

[4] Borinder, T. and $\mathrm{Bi}, \mathrm{X}$., "Softening-melting Properties of Pellets under Simulated Blast Furnace Conditions", Scandanvian Journal of Metallurgy, Vol.18, 1989, p.280-287.

[5] Grebe, K., "Development of Measures for Control of the Permeability to Gas in the Blast Furnace - Part 2: Laboratory Tests", Stahl und Eisen, Vol.170, No.13, 1987, p.620-628.

[6] Hotta, H. and Yamaoka, Y., "Softening and Melting Behaviour of Sinter and Iron Ore", Transactions ISIJ, Vol.25, 1985, p.294-301.

[7] Kaushik, P. and Fruehan, R.J., "Mixed Burden Softening and Melting Phenomena in Blast Furnace Operation Part 2 - Mechanism of Softening and Melting and Impact on Cohesive Zone", Ironmaking and Steelmaking, Vol.33, No.6, 2007, p.520-528.

[8] Nandy, B., Chandra, S., Bhattacharjee, D. and Ghosh, D., "Assessment of Blast Furnace Behaviour through Softening-melting Test", Ironmaking and Steelmaking, Vol.33, No.2, 2006, p.111-119.

[9] Chew, S.J., Liquid Flow and Softening-melting of Burden Materials in the Blast Furnace Lower Zone, PhD Thesis in Materials Science and Engineering, University of New South Wales, Sydney, 1999.

[10] Maldonado, D., Heat and Mass Transfer in the Blast Furnace Cohesive Zone : Low Temperature Cohesive Layer Experiments and Mathematical Modelling Studies at Low and High Temperatures, PhD Thesis in Materials Science and Engineering, University of New South Wales, Sydney, 2003.

[11] Zheng, X.-Q., Packing of Particles During Softening and Melting Process, PhD Thesis in Materials Science and Engineering, University of New South Wales, Sydney, 2007.

[12] Fullerton, G.D., The Softening/Melting Test Laboratory Procedures, The Broken Hill Proprietary Company Limited, 1998.

[13] Friedmann, T., Flow of Non-Newtonian Fluids through Compressible Porous Media in Centrifugal Filtration Processing, Doctor of Technical Services Thesis in Laboratory of Food Process Engineering, Swiss Federal Institute of Technology (ETH), Zurich, 1999.

[14] Ying, A., Huang, H. and Abdou, M., "Numerical Simulation of Ceramic Breeder Pebble Bed Thermal Creep Behaviour", Journal of Nuclear Materials, Vol.301-311, 2002, p.827-831.

[15] Chew, S.J., Zulli, P., Nightingale, R. and Yu, A.B., "Application of softening melting test data in blast furnace", in Proc. 2nd International Conference on Process Development in Iron and Steelmaking, Lulea, Sweden, 2004, p.405-416.

[16] Kempton, L., et al., "Simulation of macroscopic deformation using a sub-particle DEM approach", Powder Technology, Vol.223, 2012, p.19-26.

[17] Zhou, Y.C., et al., "Rolling Friction in the Dynamic Simulation of Sandpile Formation", Physica A: Statistical Mechanics and its Applications, Vol.269, No.2-4, 1999, p.536-553

[18] Cundall, P.A. and Strack, O.D.L., "A Discrete Numerical Model for Granular Assemblies", Geotechnique, Vol.29, No.1, 1979, p.47-65

[19] Allen, M.P. and Tildesley, D.J., Computer Simulation of Liquids, Oxford University Press, 1987.

Powder Technology 320C (2017) pp. 586-593 DOI information:

http://dx.doi.org/10.1016/j.powtec.2017.07.082 
[20] Jiang, M.J., Yu, H.S. and Leroueil, S., "A Simple and Efficient Approach to Capturing Bonding Effect in Naturally Microstructured Sands by Discrete Element Method", International Journal for Numerical Methods in Engineering, Vol.69, 2007, p.1158-1193.

[21] Thornton, C., Ciomocos, M.T. and Adams, M.J., "Numerical Simulations of Diametrical Compression Tests on Agglomerates", Powder Technology, Vol.140, No.3, 2004, p.258-267

[22] Khanal, M., Schubert, W. and Tomas, J., "DEM Simulation of Diametrical Compression Test on Particle Compounds", Granular Matter, Vol.7, No.2, 2005, p.83-90.

[23] Golchert, D., Moreno, R., Ghadiri, M. and Litster, J., "Effect of Granule Morphology on Breakage Behaviour During Compression", Powder Technology, Vol.143-144, 2004, p.84-96.

[24] Pizette, P., et al., "Compaction of Aggregated Ceramic Powders: From Contact Laws to Fracture and Yield Surfaces", Powder Technology, Vol.198, No.2, 2010, p.240-250

[25] Wang, J., Severtson, S. and Geil, P., "Brittle-ductile Transitions and the Toughening Mechanism in Paraffin/organo-clay Nanocomposites", Materials Science and Engineering A, Vol.467, 2007, p.172-180.

[26] Dieter, G.E., Mechanical Metallurgy, 3rd ed, McGraw-Gill, London, 1988.

[27] Tunsley, R., Measuring the Strength of Materials: Tensile Testing in Mateirals Science, 2010 Jan 12, 2010 [cited 2012 August 6]. Available from: http://suite101.com/article/measuringthe-strength-of-materials-a152343.

[28] Mishra, B.K. and Thornton, C., "Impact Breakage of Particle Agglomerates", International Journal of Mineral Processing, Vol.61, No.4, 2001, p.225-239.

[29] Seyer, W.F. and Inouye, K., "Paraffin Wax: Tensile Strength and Density at Various Temperatures", Industrial and Engineering Chemistry, Vol.27, No.5, 1935, p.567-570.

[30] Neirath, C. and Smith, R. B., "The effect of material properties on growth rates of folding and boudinage: experiments with wax models", Journal of Structural Geology, Vol. 4, No. 2, 1982, p215-229

[31] Rossetti, F., Ranalli, G. and Faccenna, C., "Rheological Properties of Paraffin as an Analogue Material for Viscous Crustal Deformation", Journal of Structural Geology, Vol.21, 1999, p.413-417. 